\title{
Effect of adenosine infusion on oxygen induced carbon dioxide retention in severe chronic obstructive pulmonary disease
}

\author{
T L Griffiths, S S D Fernando, K B Saunders
}

\begin{abstract}
Background - In normal subjects intravenous adenosine infusion has been shown to stimulate ventilation with a consequent fall in arterial partial pressure of carbon dioxide $\left(\mathrm{PaCO}_{2}\right)$, probably by an action on the carotid bodies. The objective of this study was to determine whether the increase in $\mathbf{P a C O}_{2}$ seen when patients with ventilatory failure secondary to chronic obstructive pulmonary disease (COPD) are given a high concentration of oxygen to breathe might be ameliorated by an intravenous infusion of adenosine.

Methods - Eight subjects with chronic stable ventilatory failure secondary to COPD were studied. Their mean (SE) forced expiratory volume in one second $\left(F V_{1}\right)$ was $0.63(0.12) 1$ with forced vital capacity (FVC) of $1.63(0.21) 1$. They received continuous intravenous infusions of saline and adenosine in random order, double blind. The infusions were administered for two minutes at $20 \mu \mathrm{g} / \mathrm{kg} /$ $\mathrm{min}$, increasing in increments of $20 \mu \mathrm{g} / \mathrm{kg} /$ min every two minutes to a maximum infusion rate of $80 \mu \mathrm{g} / \mathrm{kg} / \mathrm{min}$ adenosine (or an equivalent saline infusion rate), or until side effects supervened. The infusions were continued at that rate for five minutes, after which the fractional inspired oxygen $\left(\mathrm{FiO}_{2}\right)$ was raised to 0.50 during a further 20 minutes of the infusion at that rate. Haemoglobin oxygen saturation $\left(\mathrm{SaO}_{2}\right)$ and transcutaneous $\mathrm{PCO}_{2}\left(\mathrm{PtcCO}_{2}\right)$ were monitored throughout the procedure. Spirometric tests were performed before and after each infusion.
\end{abstract}

Results - Adenosine infusion was accompanied by a fall in $\mathrm{PtcCO}_{2}$ from a mean (SE) of $7.29(0.42) \mathrm{kPa}$ to $6.95(0.48) \mathrm{kPa}$ : mean difference $-0.34(95 \%$ confidence interval, -0.56 to -0.11$) \mathrm{kPa}$. During saline infusion oxygen administration resulted in an increase in transcutaneous $\mathrm{PtcCO}_{2}$ from $7.35(0.34) \mathrm{kPa}$ to $7.88(0.28)$ kPa: mean difference 0.53 (95\% CI 0.20 to 0.85$) \mathrm{kPa}$. $\mathrm{PtcCO}_{2}$ did not rise above baseline levels when oxygen was administered during the adenosine infusion. A small fall in FVC was seen following adenosine infusion.

Conclusions - The increase in $\mathbf{P t c C O}_{2}$ seen when patients with stable ventilatory failure secondary to severe COPD are given a high concentration of oxygen to breathe is counteracted by a continuous intravenous infusion of adenosine.

(Thorax 1996;51:1083-1086)

Keywords: adenosine, respiration, carbon dioxide, chronic obstructive pulmonary disease.

Adenosine is known to stimulate breathing in normal humans. ${ }^{1-3}$ This is likely to be mediated by an action on the carotid bodies ${ }^{45}$ and may relate to an effect on hypoxic chemosensitivity. ${ }^{56}$ However, the effect of this nucleoside on breathing in patients with chronic obstructive pulmonary disease (COPD) has not been reported. A common problem in the management of such patients (particularly during acute exacerbations) is an increase in the arterial carbon dioxide tension $\left(\mathrm{PaCO}_{2}\right)$ following administration of oxygen. Part of the mechanism for this may be a reduction in alveolar ventilation as a result of reduced hypoxic ventilatory drive. The postulated action of adenosine on the peripheral chemoreceptors might facilitate the maintenance of peripheral chemoreceptor drive to breathe in patients with severe COPD who require an oxygen enriched inspirate. A study was therefore designed to determine whether, in patients with ventilatory failure secondary to COPD, deterioration of carbon dioxide retention resulting from breathing a high concentration of oxygen might be avoided by a concurrent intravenous infusion of adenosine. As the effect of infused adenosine in patients with COPD has not previously been reported, patients with stable chronic disease and carbon dioxide retention were studied rather than acutely ill patients. The observations made were the clinically important end points of arterial haemoglobin oxygen saturation monitored by pulse oximetry and $\mathrm{PCO}_{2}$ which was monitored transcutaneously. Invasive ventilatory monitoring which might have altered respiratory responses ${ }^{7}$ and arterial blood sampling were avoided in this study.

\section{Methods}

SUBJECTS

After giving written informed consent, eight patients (two women) with a history of stable COPD took part in the study which was approved by the local research ethics committee. Mean (SE) forced expiratory volume in one second $\left(\mathrm{FEV}_{1}\right)$ was $0.63(0.12) 1(26(4) \%$ predicted). Percentage increase in $\mathrm{FEV}_{1}$ following $200 \mu \mathrm{g}$ inhaled salbutamol was 10 (3)\%. 
All had evidence of respiratory failure with arterial oxygen saturation $\left(\mathrm{SaO}_{2}\right)$ of 81 (5)\%. Transcutaneous carbon dioxide tension $\left(\mathrm{PtcCO}_{2}\right)$ was $7.46(0.41) \mathrm{kPa}$ breathing room air. Methylxanthines (which are specific antagonists at adenosine cell surface receptors) were withdrawn 24 hours before testing in those patients receiving these drugs. Xanthinecontaining beverages such as coffee, tea, and cola were also withheld for 12 hours before testing. Other treatment such as inhaled $\beta$ agonists, anticholinergics, and steroids were continued as usual. No subject was taking CNS depressant drugs.

\section{PROCEDURE}

The study involved the intravenous administration of saline and adenosine infusions in a random order, double blind, crossover design. Subjects were seated comfortably, breathing room air. An intravenous cannula was sited in a forearm vein for the infusion of the trial solutions. Cardiac rate and $\mathrm{SaO}_{2}$ were monitored continuously at the ear by pulse oximetry (Biox 3700e, Ohmeda, Hatfield, UK). PtcCO $_{2}$ was monitored continuously by an electrode with an operating temperature of $42^{\circ} \mathrm{C}$ placed on the inner aspect of the forearm (TCM 3, Radiometer, Copenhagen, Denmark). The transcutaneous electrode registered a fall in $\mathrm{PtcCO}_{2}$ about 45 seconds after the onset of voluntary hyperventilation. $\mathrm{PCO}_{2}$ values measured transcutaneously reflect tissue $\mathrm{PCO}_{2}$ and tend to be systematically higher than $\mathrm{PaCO}_{2} .{ }^{8}$ However, in normal subjects $\mathrm{PtcCO}_{2}$ can be used to follow changes in end tidal (and hence arterial) $\mathrm{PCO}_{2}$. Using this method of $\mathrm{PtcCO}_{2}$ measurement in a group of 10 normal young subjects we found that a change in inspirate from room air to gas with inspired oxygen fraction $\left(\mathrm{FIO}_{2}\right)$ of 0.1 resulted in changes in $\mathrm{PtcCO}_{2}$ of 0.49 (0.15) and end tidal $\mathrm{PCO}_{2}$ of $0.48(0.16) \mathrm{kPa}$ (95\% confidence intervals for the difference between the transcutaneous and tidal responses was -0.17 to $0.11 \mathrm{kPa}$, unpublished observations). Thus, this is an accurate method for following changes in $\mathrm{PCO}_{2}$ of similar magnitude to those we report. Values of $\mathrm{SaO}_{2}$ and $\mathrm{PtcCO}_{2}$ were recorded at the end of each minute throughout the experiment. The electrocardiograph was monitored continuously.

When $\mathrm{PtcCO}_{2}$ and $\mathrm{SaO}_{2}$ had been observed to be stable for three minutes the subjects commenced a continuous intravenous infusion of either adenosine $2 \mathrm{mg} / \mathrm{ml}$ in saline solution $(150 \mathrm{mmol} / \mathrm{l})$ or placebo saline $(150 \mathrm{mmol} / \mathrm{l})$. The study drugs were loaded into syringes and delivered using a microprocessor controlled syringe driver (Harvard 22, Harvard Apparatus Ltd, Edenbridge, Kent, UK). The infusion rate was calculated to be equivalent to adenosine delivery rates of $20,40,60$, and $80 \mu \mathrm{g} / \mathrm{kg} / \mathrm{min}$ in two minute steps for both infusions. After five minutes at the $80 \mu \mathrm{g} / \mathrm{kg} / \mathrm{min}$ level, additional oxygen was administered via a Venturi face mask to provide an $\mathrm{FiO}_{2}$ of 0.5 . The $\mathrm{FIO}_{2}$ delivered by the mask was checked using a fast responding mass spectrometer sampling via a capillary tube from the anterior nares. The infusion was continued whilst breathing this high inspired oxygen concentration for $20 \mathrm{~min}$ utes. If unpleasant side effects such as headache, flushing, or dyspnoea were experienced the infusion rate was reduced to a level felt to be tolerable by the subject. After the 20 minutes of oxygen administration, the oxygen and infusion were discontinued and the patient rested for at least one hour. The procedure was then repeated with the second infusion. $\mathrm{FEV}_{1}$ and FVC were measured before and at the end of each infusion with a turbine spirometer (Micro Spirometer, Micro Medicals, Rochester, UK).

\section{DATA ANALYSIS}

Values reported are mean (SE) with $95 \%$ confidence intervals $(95 \% \mathrm{CI})$ for main results. Observations were analysed at three time points during the experiment - that is, at rest, at the end of the infusion alone, and at the end of the infusion + oxygen for each treatment. Analysis of variance with repeated measures using the three time points as the repeated measures factors and saline and adenosine as the treatment factors - was used to investigate changes in $\mathrm{PtcCO}_{2}$ with experimental time point and drug given. The Student's paired $t$ test was used to investigate differences between the experimental observations and their respective baseline values. The paired $t$ test was also used to determine differences between mean values of observations between the two arms of the study. A $p$ value of $<0.05$ was regarded as significant.

\section{Results}

In three subjects the maximum infusion rate of adenosine was reduced because of side effects, primarily dyspnoea. In these subjects the final infusion rates were 70,60 , and $20 \mu \mathrm{g} / \mathrm{kg} / \mathrm{min}$. The spirometric values before and after the saline infusion showed no statistically significant changes with $\mathrm{FEV}_{1} 0.62(95 \% \mathrm{CI} 0.30$ to 0.94$) 1$ before and 0.60 (95\% CI 0.26 to $0.94) 1$ after the infusion and FVC $1.60(95 \%$ CI 1.04 to 2.16$) 1$ before and 1.53 (95\% CI 0.94 to 2.12 ) 1 after. $\mathrm{FEV}_{1}$ did not change significantly with adenosine infusion, being 0.65 (95\% CI 0.33 to 0.97$) 1$ before and 0.60 $(95 \%$ CI 0.28 to 0.92$) 1$ after the infusion. However, there was a small but statistically significant fall in FVC following adenosine infusion from 1.67 (95\% CI 1.03 to 2.31 ) l before to 1.57 (95\% CI 0.93 to 2.21$) 1$ after the infusion (mean difference $-0.10(95 \% \mathrm{CI}$ -0.17 to -0.03$) \mathrm{l} ; \mathrm{p}<0.02)$. The heart rate at rest, at the end of drug infusion, and at the end of infusion with oxygen was 85 (9), 87 (8), and 86 (7) beats/min, respectively, for saline and 86 (9), 85 (9), and 87 (7) beats $/ \mathrm{min}$, respectively, for adenosine. The differences between the two infusions at each point were not statistically significant.

Analysis of variance showed a significant effect of experimental time point on $\mathrm{SaO}_{2}$ $(p<0.0001)$. There was, however, no significant effect of the drugs on this relationship with 
Figure 1 Mean haemoglobin oxygen saline (O) and adenosine (口) infusions. The 0.50 to the inspirate is shown by the shaded bar. The adenosine and rates are given at two minute intervals. saturation plotted during addition of oxygen at FIO equivalent saline infusion

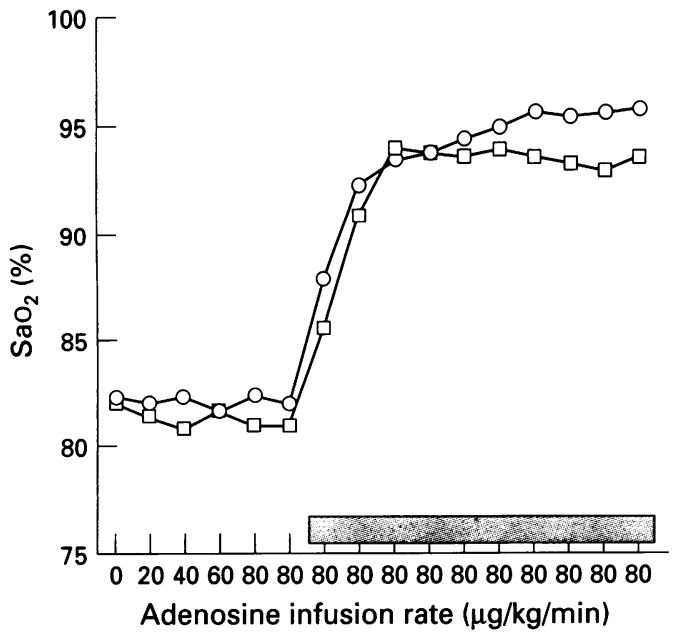

Figure 2 Mean transcutaneous $\mathrm{PCO}_{2}$ plotted during saline $(\mathrm{O})$ and adenosine ( $\square$ ) infusions. The addition of oxygen at $\mathrm{FIO}_{2} 0.50$ to the inspirate is shown by the shaded bar. The adenosine and equivalent saline infusion rates are given at two minute intervals.

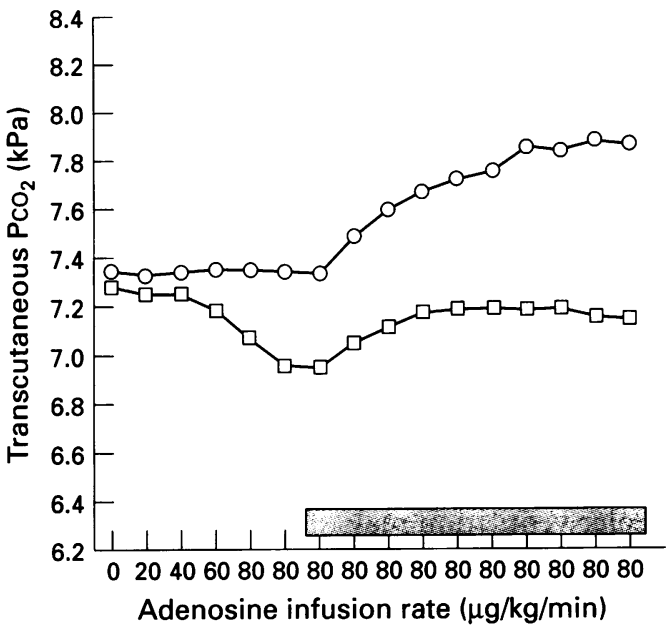

$\mathrm{SaO}_{2}$ rising significantly above baseline during elevation of the $\mathrm{FIO}_{2}$ on both treatments. The $\mathrm{SaO}_{2}$ at two minute intervals throughout the experiment is shown in fig 1 . There was a significant effect of experimental time point on $\mathrm{PtcCO}_{2}(\mathrm{p}<0.001)$ with a significant treatment effect $(p<0.01)$. The $\mathrm{PtcCO}_{2}$ at two minute intervals throughout the experiment is shown in fig 2.

Mean $\mathrm{PtcCO}_{2}$ at rest was $7.35(95 \%$ CI 6.56 to 8.14$) \mathrm{kPa}$ for saline and 7.30 (95\% CI 6.33 to 8.26 ) $\mathrm{kPa}$ for adenosine (mean difference between treatments 0.05 ( $95 \%$ CI -0.33 to $0.43) \mathrm{kPa}$; not significant), during lone infusion it was $7.35(95 \% \mathrm{CI} 6.56$ to 8.14$) \mathrm{kPa}$ for saline and 6.95 (95\% CI 5.89 to 8.01$) \mathrm{kPa}$ for adenosine (mean difference between treatments 0.40 (95\% CI -0.03 to 0.83$) \mathrm{kPa}$; $\mathrm{p}<0.06$ ), and during infusion + oxygen it was $7.89(95 \%$ CI 7.24 to 8.54$) \mathrm{kPa}$ for saline and 7.15 (95\% CI 6.01 to 8.29$) \mathrm{kPa}$ for adenosine (mean difference between treatments 0.74 ( $95 \% \mathrm{CI} 0.12$ to 1.36 ) $\mathrm{kPa}$; $<0.05$ ). During saline infusion the rise in $\mathrm{PtcCO}_{2}$ during hyperoxia was seen in seven of the eight subjects. During adenosine infusion a fall in $\mathrm{PtcCO}_{2}$ was seen in seven subjects with a subsequent rise in $\mathrm{PtcCO}_{2}$ in six subjects under hyperoxic conditions.

The mean changes from baseline to end of infusion and from baseline to infusion + oxygen, together with the differences between these responses on the two drugs, are shown in table 1. During the saline arm of the study there was, overall, a significant rise in $\mathrm{PtcCO}_{2}$ which was greater than that seen with adenosine. In contrast, $\mathrm{PtcCO}_{2}$ fell significantly during the lone adenosine infusion, this fall being greater than the change seen with saline. Although the rise in $\mathrm{PtcCO}_{2}$ seen with the addition of oxygen to the inspirate during the saline infusion was twice as great as when oxygen was added during the adenosine infusion, the mean difference between treatments of $0.33(95 \% \mathrm{CI}-0.04$ to 0.70$) \mathrm{kPa}$ just failed to achieve statistical significance $(p=0.06)$.

The stability of mean $\mathrm{PtcCO}_{2}$ during the placebo saline infusion ( $95 \%$ confidence interval for the difference between rest and saline infusion -0.15 to $0.15 \mathrm{kPa}$ ) suggests that there was no systematic drift of $\mathrm{PtcCO}_{2}$ sensing over that time period.

\section{Discussion}

We were interested to determine whether intravenous infusion of adenosine would ameliorate the increase seen in $\mathrm{PCO}_{2}$ when patients with ventilatory failure secondary to COPD are given a high concentration of oxygen to breathe. Our findings suggest, firstly, that intravenous infusion of adenosine whilst breathing room air is accompanied by a fall in $\mathrm{PCO}_{2}$ and, secondly, that when a hyperoxic inspirate is administered to patients with ventilatory failure concomitant intravenous adenosine infusion prevents a rise in $\mathrm{PCO}_{2}$ above baseline levels in spite of a small but significant reduction in dynamic lung volumes. Significant effects of adenosine on $\mathrm{SaO}_{2}$ were not encountered in our patients.

With infusion of adenosine both $\mathrm{FEV}_{1}$ and FVC fell slightly (FVC significantly so), suggesting that intravenous adenosine may have a small effect on airway calibre in patients with COPD. This is in keeping with the observation that intravenous bolus doses of adenosine can provoke bronchospasm in patients with COPD. ${ }^{9}$ Interestingly, inhaled adenosine causes bronchoconstriction in asthmatic patients $^{10}$ but intravenous infusion of up to $50 \mu \mathrm{g} / \mathrm{kg} / \mathrm{min}$ does not alter their airway conductance. ${ }^{11}$ Thus, the effect we have found may reflect a susceptibility of the bronchial smooth muscle in patients with COPD to the bronchoconstrictor effects of adenosine. Whilst adenosine infusion was not accompanied by detrimental changes in $\mathrm{SaO}_{2}$ in our subjects, the finding of reduced spirometric values suggests that adenosine infusion should be used with caution in patients with very severe airflow limitation.

Another important effect of adenosine infusion which might affect oxygen delivery is an increased heart rate which has been described in normal subjects. ${ }^{231213} \mathrm{We}$, however, did not detect any significant difference in heart rate between saline and adenosine infusions in our patients with COPD, which may reflect the relatively low infusion rate used in the present study. We monitored changes in $\mathrm{PCO}_{2}$ transcutaneously. Transcutaneous monitoring has 
Table 1 Changes in transcutaneous carbon dioxide tension $\left(\mathrm{PtcCO}_{2}\right)$ during saline and adenosine infusions with and without the addition of oxygen to the inspirate $\left(\mathrm{FIO}_{2} \mathrm{0.50}\right)$

\begin{tabular}{|c|c|c|c|}
\hline & $\begin{array}{l}\text { Saline infusion } \\
(95 \% \text { CI })\end{array}$ & $\begin{array}{l}\text { Adenosine infusion } \\
(95 \% \mathrm{CI})\end{array}$ & $\begin{array}{l}\text { Difference between infusions } \\
(95 \% \mathrm{CI})\end{array}$ \\
\hline $\begin{array}{l}\text { Pre-infusion } \mathrm{PtccO}_{2}(\mathrm{kPa}) \\
\text { Change in } \mathrm{PtcCO}_{2} \text { from rest to end } \\
\text { infusion }(\mathrm{kPa})\end{array}$ & $\begin{array}{l}7.35(6.56 \text { to } 8.14) \\
0.00(-0.15 \text { to } 0.15)\end{array}$ & $\begin{aligned} & 7.30(6.33 \text { to } 8.26) \\
&-0.34(-0.57 \text { to }-0.11)^{* *}\end{aligned}$ & $\begin{array}{l}0.05(-0.33 \text { to } 0.43) \\
0.34(0.03 \text { to } 0.65)^{*}\end{array}$ \\
\hline $\begin{array}{l}\text { Change in } \mathrm{PtcCO}_{2} \text { from rest to end } \\
\text { infusion }+\mathrm{O}_{2}(\mathrm{kPa})\end{array}$ & $0.53(0.22 \text { to } 0.84)^{* *}$ & $-0.14(-0.48$ to 0.20$)$ & $0.66(0.26 \text { to } 1.06)^{* *}$ \\
\hline
\end{tabular}

${ }^{*} \mathrm{p}<0.05 ;{ }^{* *} \mathrm{p}<0.01$

been successfully used by previous investigators to follow changes in $\mathrm{PCO}_{2}$ during adenosine infusion. ${ }^{312}$ Heating the electrode produces local hyperaemia and this may be why infusion of adenosine does not alter the relationship between end tidal $\mathrm{PCO}_{2}$ and transcutaneous $\mathrm{PCO}_{2}$ in normal subjects. ${ }^{14}$ As measurement of transcutaneous oxygen tension may be affected by adenosine under hypoxic conditions, ${ }^{14}$ oxygen saturation was used to follow oxygenation. The mechanism of the effect of adenosine infusion on $\mathrm{PtcCO}_{2}$ has not been addressed in this study. However, in normal subjects infusion of adenosine up to $80 \mu \mathrm{g} / \mathrm{kg} / \mathrm{min}$ does not affect either oxygen uptake or carbon dioxide production but is accompanied by a fall in estimated $\mathrm{PaCO}_{2}{ }^{6}{ }^{6}$ which implies an increase in alveolar ventilation. In the present study the lack of improvement in $\mathrm{SaO}_{2}$ with adenosine infusion argues against a favourable change in the ventilation/perfusion relationships of the lung. Thus, increased alveolar ventilation may be the explanation for the effect of adenosine on $\mathrm{PtcCO}_{2}$ found in this study. In normal subjects a reduction in the ratio of dead space ventilation to total ventilation is seen with adenosine. ${ }^{313}$ Such an alteration might be particularly important in patients with COPD.

In normal subjects the stimulation of breathing by adenosine ${ }^{1-3}$ may be mediated by carotid body stimulation. ${ }^{245}$ Our findings are consistent with a similar effect in patients with COPD, the $\mathrm{PtcCO}_{2}$ being maintained below baseline even when a hyperoxic gas mixture is breathed. Thus, it is possible that by supplying exogenous adenosine, carotid body discharge may be maintained even under hyperoxic conditions when the peripheral chemoreceptors are normally silenced. ${ }^{15-17}$

Carbon dioxide retention is an important complication of oxygen therapy in patients with ventilatory failure secondary to COPD. To our knowledge, this is the first description of adenosine being used to ameliorate oxygen induced hypercapnia. The changes in $\mathrm{PtcCO}_{2}$ we report are small and thus the effect of adenosine in this group of patients is of little clinical importance per se. However, the results do suggest that it is possible to attenuate the physiological response to hyperoxia in severe COPD. We have shown the short term action of adenosine in patients with stable ventilatory failure, but the importance of the bronchoconstriction we observed and whether tachyphylaxis to the effects of adenosine might occur during prolonged infusion merit further investigation. It is a matter of conjecture whether a similar beneficial effect on $\mathrm{PCO}_{2}$ would be seen if adenosine were to be used in conjunction with oxygen treatment during acute on chronic exacerbations of COPD when the drive to breathe may already be high.

In conclusion, we have found that a continuous intravenous infusion of adenosine results in a fall in $\mathrm{PtcCO}_{2}$ and counteracts the rise in $\mathrm{PtcCO}_{2}$ seen in patients with ventilatory failure secondary to COPD when breathing an oxygen rich inspirate. A small reduction in dynamic lung volumes is also seen during adenosine infusion in these patients.

This study was supported by a project grant from the British Lung Foundation (BLF)

1 Watt $\mathrm{AH}$, Routledge PA. Adenosine stimulates respiration in man. Br f Clin Pharmacol 1985;20:503-6.

2 Biaggioni I, Olafsson B, Robertson MR, Hollister AS, Robertson D. Cardiovascular and respiratory effects of adenosine in conscious man: evidence for chemoreceptor activation. Circ Res 1987;61:779-86.

3 Fuller RW, Maxwell DL, Conradson T-BG, Dixon CMS, Barnes PJ. Circulatory and respiratory effects of infused adenosine in conscious man. Br $\mathcal{F}$ Clin Pharmacol 1987; 24:309-17.

4 Watt AH, Reid PG, Stephens MR, Routledge PA. Adenosine induced respiratory stimulation in man depends on site of infusion. Evidence for an action on the carotid body? Br 7 Clin Pharmacol 1987;23:486-90.

5 Griffiths TL, Warren SJ, Chant ADB, Holgate ST. Ventilatory effects of hypoxia and adenosine infusion in patients after bilateral carotid endarterectomy. Clin Sci 1990;78: 25-31

6 Maxwell DL, Fuller RW, Nolop KB, Dixon CMS, Hughes JMB. Effects of adenosine on ventilatory responses to hypoxia and hypercapnia in humans. $\mathcal{F}$ Appl Physiol 1986; 61:1762-6.

7 Askanazi J, Silverberg PA, Foster RJ, Hyman AI, MilikEmili J, Kinney JM. Effects of respiratory apparatus on breathing pattern. F Appl Physiol 1980;48:577-80.

8 Stradling JR, Nicholl CG, Cover D, Hughes JMB. Speed of response and accuracy of two transcutaneous carbon dioxide monitors. Bull Eur Physiopathol Respir 1983;19: 407-10.

9 Drake I, Routledge PA, Richards R. Bronchospasm induced by intravenous adenosine. Hum Exp Toxicol 1994;13:2635

10 Mann JS, Holgate ST, Renwick AG, Cushley MJ. Airway effects of purine nucleosides and nucleotides and release with bronchial provocation in asthma. F Appl Physiol 1986; 61:1667-76.

11 Larsson K, Sollevi A. Influence of infused adenosine on bronchial tone and bronchial reactivity in asthma. Chest 1988;93:280-4

12 Maxwell DL, Fuller RW, Conradson T-B, Dixon CMS, Aber V, Hughes JMB, et al. Contrasting effects of two xanthines, theophylline and enprofylline, on the cardiorespiratory stimulation of infused adenosine in man. Acta Physiol Scand 1987;131:459-65.

13 Reid PG, Watt WH, Routledge PA, Smith AP. Intravenous infusion of adenosine but not inosine stimulates respiration in man. Br $\mathcal{F}$ Clin Pharmacol 1987;23:331-8.

14 Griffiths TL, Rowlands DE, Kapoor A, Holgate ST. Effect of adenosine on transcutaneous gas measurement. $\mathrm{Am}$ Rev Respir Dis 1991;143:A73.

15 Cunningham DJC, Lloyd BB, Miller JP, Young JM. The time course of human ventilation after transient changes in $\mathrm{P}_{\mathrm{A}} \mathrm{CO}_{2}$ at two values of $\mathrm{P}_{\mathrm{A}} \mathrm{O}_{2} . \mathcal{J}$ Physiol (London) 1965; in $\mathrm{P}_{\mathrm{A}} \mathrm{CO}_{2}$ at

16 Gelfand R, Lambertson JC. Dynamic respiratory response to abrupt change of inspired $\mathrm{CO}_{2}$ at normal and high $\mathrm{PO}_{2}$. Appl Physiol 1973;35:903-13.

17 Miller JP, Cunningham DJC, Lloyd BB, Young JM. The transient respiratory effects in man of sudden changes in alveolar $\mathrm{CO}_{2}$ in hypoxia and in high oxygen. Respir Physiol $1974 ; 20: 17-31$ 